\title{
Educação inclusiva: uma questão constitucional do bem-estar e da dignidade das pessoas
}

\section{Inclusive education. A constitutional issue of people's welfare and dignity}

\author{
Rodrigo Rios Faria de Oliveira ${ }^{1 *}$, Letícia Maria de Maia Resende ${ }^{2}$
}

\begin{abstract}
RESUMO
O presente artigo analisa a educação inclusiva como questão de ordem constitucional. Assim, estabelece uma relação entre essa modalidade de ensino e aprendizagem, em que as diversidades são compreendidas e valorizadas, e os princípios da dignidade da pessoa humana, basilar para o desenvolvimento do Estado Democrático de Direito, e do bem-estar social, admitido, dentre outros, como objetivo fundamental da República brasileira. O texto, dividido em três partes, realiza-se pela metodologia analítica e argumenta ser a educação inclusiva um instrumento capaz de fomentar o respeito às diversidades presentes no tecido social. Logo, o Estado deve lançar mão dessa dinâmica educativa a fim de que a pluralidade típica da democracia seja realidade, respeitando-se a dignidade da pessoa humana e promovendo um ambiente social sem preconceitos e discriminação de quaisquer categorias.
\end{abstract}

Palavras-chave: bem-estar; dignidade humana; educação inclusiva; Estado Democrático de Direito.

\begin{abstract}
This article analyzes inclusive education as a constitutional issue. Thus, it establishes a relationship between this modality of teaching and learning, in which diversities are understood and valued, and the principles of human dignity, fundamental for the development of the Democratic State, and of social welfare, admitted, among others, as a fundamental objective of the Brazilian Republic. The text, divided into three parts, uses the analytical methodology and argues that inclusive education is an instrument capable of promoting respect for the diversity present in the social local. Therefore, the State must make use of this educational dynamic so that the plurality typical of democracy becomes a reality, respecting the dignity of the human person and promoting a social environment without prejudice and discrimination of any category.
\end{abstract}

Key-words: welfare; human dignity; inclusive education; Democratic State.

\footnotetext{
${ }^{1}$ Universidade do Vale do Sapucaí. *E-mail: profdrrodrigooliveira@gmail.com

${ }^{2}$ Faculdade de Direito do Sul de Minas. E-mail: lemaia2003@yahoo.com.br
} 


\section{INTRODUÇÃO}

O presente artigo adota como tema central questões de ordem constitucional relacionadas ao respeito à diversidade, apresentando a educação inclusiva, modalidade de ensino e aprendizagem que leva em consideração as diversidades das pessoas, a qual, com base numa rede de apoio composta pela família, educadores, instituição de ensino e sociedade, tem capacidade de atender às necessidades individuais e desenvolver as potencialidades das pessoas.

O texto analisa a educação inclusiva segundo o princípio da dignidade da pessoa humana, basilar para o Estado Democrático de Direito, e o objetivo fundamental de bemestar social, ambos previstos na Constituição da República Federativa do Brasil de 1988 em seus artigos $1^{\circ}$ e $3^{\circ}$, respectivamente.

Desse modo, dividido em três seções, o artigo observa, de modo geral, os princípios mencionados e a educação inclusiva. Assim, a primeira parte trata do bemestar social e a relação que estabelece com as prestações positivas do Estado para que toda a sua estrutura possibilite a fruição e o exercício dos direitos fundamentais. Na segunda seção, o texto aborda a dignidade humana, princípio que, ao propiciar especial atenção para a pessoa humana como sujeito de direitos e obrigações no plano jurídiconormativo, é de fundamental importância para o pleno funcionamento do ente estatal.

Por fim, considerando a mistura típica do Estado Democrático de Direito, a educação inclusiva é analisada como um instrumento a ser usado pelo Estado a fim de que as diferenças sejam transformadas em diversidades, ensejando o devido respeito às pluralidades e, consequentemente, a promoção mais efetiva da dignidade humana. Esse processo, logo, reflete-se na sociedade, fazendo com que a promoção do bem-estar social se torne uma realidade concreta para todas as pessoas.

\section{O PRINCÍPIO DO BEM-ESTAR}

O princípio do bem-estar possui o objetivo de a ação moral dever ser o bem-estar em todos os níveis, sendo ele intelectual, físico e moral. Por esse referido princípio, todo ser humano possui o direito de acesso, desde quando nasce até o momento do seu falecimento, a vários bens e serviços, onde os mesmos devem vir a ser fornecidos pelo 
Estado direta ou indiretamente mediante o poder que o ente estatal possui de regulamentação sobre a sociedade civil.

São as denominadas prestações positivas ou mesmo os direitos de segunda geração, em que estão inclusos a gratuidade e a universalidade do acesso à educação, a assistência médica, o auxílio ao desempregado, aposentadoria, proteção à maternidade, infância e também à velhice.

A Constituição Federal de 1988 possui como intenção constituir a República Federativa do Brasil em um Estado Democrático e Social de Direito, onde se tem uma estrutura jurídica que possui como base princípios garantidores dos direitos fundamentais.

Barroso afirma que:

É o símbolo de uma história de sucesso: a transição de um Estado autoritário, intolerante e muitas vezes violento para um Estado democrático de direito. Sob sua vigência, vêm-se realizando eleições presidenciais, por voto direto, secreto e universal, com debate público amplo, participação popular e alternância de partidos políticos no poder. Mais que tudo, a Constituição assegurou ao país a estabilidade institucional que tanto faltou ao longo da república. (BARROSO, 2009, p.80)

Existe no preâmbulo da Constituição Federal de 1988 a positivação de várias normas próprias de um Estado de bem-estar social. Sobre o assunto afirma Mendes:

O preâmbulo é uma espécie de Constituição da Constituição, funcionando como uma "ponte no tempo", seja para evocar ou esconjurar o passado, a depender das circunstâncias históricas de cada processo constituinte; seja para falar ao presente, ocasionalmente orientando desejos; seja, enfim, para contemplar tanto o presente quanto o futuro e, com relação a este, ademais, para antecipar, quanto possível, o encontro de um povo com esse almejado porvir (MENDES et. al., 2010, p.75).

O constituinte, quando institui o Estado Democrático de Direito, busca, além da formulação formal de uma nova Constituição, o rompimento com o regime ditatorial que destruía os ideais democráticos e matava os direitos fundamentais que até então já haviam sido alcançados. Nesse sentido, o Estado de bem-estar social foi resgatado, uma vez que o modelo estatal é baseado na garantia e na concretização dos direitos fundamentais. Como exemplo, tem-se os direitos inscritos no artigo $3^{\circ}$ da referida Constituição, que possui como objetivo terminar com a pobreza e a marginalização, diminuir as desigualdades sociais e regionais e vir a promover o bem de todos. 
O Estado Democrático de Direito é uma organização política do poder que se assenta em vários princípios elementares, inclusive no princípio do bem-estar social, em que a sua efetivação é o objetivo e o motivo pelo qual foi criado. Alguns princípios que anteriormente não eram suficientes na realidade do Estado Liberal mereceram novo sentido no Estado Democrático de Direito, sendo assim possível a permanência dos mesmos, vindo a ser ampliados.

Por ser suprema a Constituição Federal, seus princípios e fundamentos devem orientar a atividade hermenêutica, servindo de manutenção e aumento da dignidade da pessoa humana, de forma a oferecer efetividade máxima aos direitos fundamentais.

Sobre o assunto, afirma Barroso:

A Constituição, portanto, é dotada de superioridade jurídica em relação a todas as normas do sistema e, como consequência, nenhum ato jurídico pode subsistir validamente se for com ela incompatível. Para assegurar essa supremacia, a ordem jurídica contempla um conjunto de mecanismos conhecidos como jurisdição constitucional, destinados a, pela via judicial, fazer prevalecer os comandos contidos na Constituição. Parte importante da jurisdição constitucional consiste no controle de constitucionalidade, cuja finalidade é declarar a invalidade e paralisar a eficácia dos atos normativos que sejam incompatíveis com a Constituição. (BARROSO, 2009, p.85)

\section{DA DIGNIDADE DA PESSOA HUMANA}

A dignidade envolve vidas, pois muitos já mataram e já morreram por dignidade. Para During, dignidade é uma "qualidade intrínseca da pessoa humana, é irrenunciável e inalienável, constituindo elemento que qualifica o ser humano como tal e dele não pode ser destacado" (DURIG apud SARLET, 2011, p. 42). O referido princípio encontra-se previsto na Constituição Federal do Brasil como um dos fundamentos da república brasileira, em seu artigo $1^{\circ}$, in verbis:

Art. $1^{\circ}$ A República Federativa do Brasil, formada pela união indissolúvel dos Estados e Municípios e do Distrito Federal, constituise em Estado Democrático de Direito e tem como fundamentos: [...]

III - a dignidade da pessoa humana; 
Os direitos individuais do homem tiveram origem no antigo Egito e Mesopotâmia, onde já havia alguns mecanismos que eram utilizados para fazer a proteção do homem como ser individual na relação com o Estado.

Portanto, o maior desenvolvimento das declarações de direitos humanos fundamentais se deu efetivamente do período posterior ao século XVIII até o século XX. Já no país, a Constituição Política do Império do Brasil de 1824 trazia a palavra dignidade em seus artigos 107 e 108, porém tinham validade somente para o Imperador e para a Imperatriz.

Já na Constituição da República Federativa do Brasil de 1967, no artigo 157, inciso II, foi feita referência à valorização do trabalho, sendo o mesmo uma condição da dignidade humana.

O princípio da dignidade da pessoa humana é um dos princípios maiores que estão fundamentados na Constituição Federal de 1988, já que é considerado um dos fundamentos da República Federativa do Brasil.

Sobre o assunto afirma Nelson Nery Júnior:

Esse princípio não é apenas uma arma de argumentação, ou uma tábua de salvação para a complementação de interpretações possíveis de normas postas. Ele é a razão de ser do Direito. Ele se bastaria sozinho para estruturar o sistema jurídico. Uma ciência que não se presta para prover a sociedade de tudo quanto é necessário para permitir o desenvolvimento integral do homem, que não se presta para colocar o sistema a favor da dignidade humana, que não se presta para servir ao homem, permitindo-lhe atingir seus anseios mais secretos, não se pode dizer Ciência do Direito. Comprometer-se com a dignidade do ser humano é comprometer-se com sua Vida e com sua liberdade. É o princípio fundamental do direito. É o primeiro. O mais importante (NERY JÚNIOR, 2006, p.119).

Com os mesmos passos de vários outros países, a Constituição Federal Brasileira dá ao princípio da dignidade da pessoa humana um caráter normativo amplo, já que demonstra reflexo mediante todo o sistema político, social e também jurídico. Além disso, traz de forma veemente a importância que o Estado consegue atribuir à pessoa humana, já que aquele existe pelo motivo desta. Sobre o ser humano como o motivo de toda a atividade do estado, afirma Gustavo Tepedino:

A dignidade da pessoa humana torna-se o objetivo central da República, funcionalizando em sua direção a atividade econômica privada, a empresa, a propriedade, as relações de consumo. Trata-se não mais do 
individualismo do século XVIII, marcado pela supremacia da liberdade individual, mas de um solidarismo inteiramente diverso, em que a autonomia privada e o direito subjetivo são remodelados em função dos objetivos sociais definidos pela Constituição e que, em última análise, voltam-se para o desenvolvimento da personalidade e para a emancipação do homem (TEPEDINO, 2011, p.501).

O referido princípio é de fundamental importância para o pleno funcionamento do Estado. Inclusive, vem sido abordado com bastante frequência pelas mídias e demais meios de comunicação, os quais abrem espaço para vários juristas comentarem e analisarem de forma ampla a dignidade da pessoa humana.

A Constituição Federal de 1988 traz como fundamento do Estado Democrático de Direito a dignidade da pessoa humana, porém alguns autores entendem que a mesma também deve ser um valor constitucional, conforme afirma Pietro de Jesús Lora Alarcón:

O ser humano não pode ser objeto de humilhações ou ofensas, mas se deve reconhecer na sua essência de liberdade, responsabilidade e finalidade em si mesmo. Em função disso, a impossibilidade de degradação do ser humano impede redução do homem a mero objeto do Estado ou de terceiros, o que incluía impossibilidade de coisificação da pessoa, um ponto de não retorno da pessoa ao estado de simples coisa (ALARCÓN, 2014, p. 255).

A superioridade dos princípios da Constituição é sustentada pela possibilidade de criação de um sistema interno de hierarquia que organiza os termos constitucionais com base em sua importância, apesar de todos serem compreendidos como de relevância fundamental. Desse modo, os princípios estariam dispostos num patamar acima das outras questões, desemprenhando, assim, uma força vinculante maior, principalmente no que diz respeito à atividade interpretativa. Sobre o assunto, afirma Alexandre de Moraes:

Esse fundamento afasta a ideia de predomínio das concepções transpessoalistas de Estado e Nação, em detrimento da liberdade individual. A dignidade é um valor espiritual e moral inerente à pessoa, que se manifesta singularmente na autodeterminação consciente e responsável da própria vida e que traz consigo a pretensão ao respeito por parte das demais pessoas, constituindo-se um mínimo invulnerável que todo estatuto jurídico deve assegurar, de modo que, somente excepcionalmente, possam ser feitas limitações ao exercício dos direitos fundamentais, mas sempre sem menosprezar a necessária estima que merecem todas as pessoas enquanto seres humanos (MORAES, 2013, p.98).

$\mathrm{O}$ respeito ao princípio da dignidade da pessoa humana enseja a proteção à integridade física, moral e também individual e espiritual do ser humano. Portanto, visto que o Direito possui sua razão de existir no homem, deve o mesmo ser utilizado como 
instrumento garantidor com o fim de impedir todo tipo de degradação do gênero humano. Ainda sobre o referido princípio, afirma José Afonso da Silva:

A norma constitucional do artigo $5^{\circ}$, inciso LVII, garante a presunção de inocência por meio de um enunciado negativo universal: "ninguém será considerado culpado até o trânsito em julgado de uma sentença penal condenatória". O trânsito em julgado se dá quando a decisão não comporta mais recurso ordinário, especial ou extraordinário (SILVA, 2008, p.159).

Sobre a ação imediata dos princípios, isto acontece decorrente do funcionamento de parâmetros interpretativos e integrativos, já que demonstram suporte à ordem jurídica sob o aspecto de sistema. Luiz Roberto Barroso explica que:

A dogmática moderna avaliza o entendimento de que as normas jurídicas, em geral, e as normas constitucionais, em particular, podem ser enquadradas em duas categorias diversas: as normas-princípio e as normas-disposição. As normas-disposição, também referidas como regras, têm eficácia restrita às situações específicas às quais se dirigem. Já as normas-princípio, ou simplesmente princípios, têm, normalmente, maior teor de abstração e uma finalidade mais destacada dentro do sistema (BARROSO, 2009, p.153).

Sarlet conceitua a dignidade da pessoa humana como:

A qualidade intrínseca e distintiva reconhecida em cada ser humano que o faz merecedor do mesmo respeito e consideração por parte do Estado e da comunidade, implicando, neste sentido, um complexo de direitos e deveres fundamentais que assegurem a pessoa tanto contra todo e qualquer ato de cunho degradante e desumano, como venham a lhe garantir as condições existenciais mínimas para uma vida saudável, além de propiciar e promover sua participação ativa e corresponsável nos destinos da própria existência e da vida em comunhão com os demais seres humanos (SARLET, 2011, p.61).

Conforme afirma Sarlet, somente depois da Segunda Guerra Mundial as Constituições começam a reconhecer expressamente a dignidade da pessoa humana, mas ainda nos dias de hoje há países que não realizaram tal reconhecimento por meio de previsão em instrumentos normativos. Sobre o assunto afirma Barroso:

O princípio da dignidade da pessoa humana identifica um espaço de integridade moral a ser assegurado a todas as pessoas por sua só existência no mundo. É um respeito à criação, independente da crença que se professe quanto à sua origem. A dignidade relaciona-se tanto com a liberdade e valores do espírito como com as condições materiais de subsistência. O desrespeito a este princípio terá sido um dos estigmas do século que se encerrou e a luta por sua afirmação um símbolo do novo tempo. Ele representa a superação da intolerância, da discriminação, da exclusão social, da violência, da incapacidade de aceitar o outro, o diferente, na plenitude de sua liberdade de pensar, de 
ser e de criar. Dignidade da pessoa humana expressa um conjunto de valores civilizatórios incorporados ao patrimônio da humanidade. $\mathrm{O}$ conteúdo jurídico do princípio vem associado aos direitos fundamentais, envolvendo aspectos dos direitos individuais, políticos e sociais. Seu núcleo material elementar é composto do mínimo existencial, locução que identifica o conjunto de bens e utilidades básicas para a subsistência física e indispensável ao desfrute da própria liberdade. Aquém daquele patamar, ainda quando haja sobrevivência, não há dignidade. $\mathrm{O}$ elenco de prestações que compõem o mínimo existencial comporta variação conforme a visão subjetiva de quem o elabore, mas parece haver razoável consenso de que inclui: renda mínima, saúde básica e educação fundamental. Há ainda, um elemento instrumental, que é o acesso à justiça, indispensável para a exigibilidade e efetivação dos direitos (BARROSO, 2009, p.28).

Desse modo, é possível perceber a preocupação que a Constituição Federal de 1988 traz acerca do princípio da dignidade da pessoa humana, principalmente ao fato de colocá-lo em um ponto de destaque, como um verdadeiro fundamento da República Federativa do Brasil que é. Assim, partindo da perspectiva de Estado Democrático de Direito, o texto constitucional apresenta o ser humano como alvo de uma moderna estrutura jurídica e contribui para inadmitir qualquer prática que o reduza a condição de coisa ou que o prive dos meios necessários à sua manutenção.

Maria Garcia afirma que:

$\mathrm{Na}$ Constituição brasileira, a dignidade da pessoa humana figura entre os princípios fundamentais que estruturam o Estado como tal, portanto, inserindo-se entre os valores superiores que fundamentam o Estado, a dignidade da pessoa representará o crivo pelo qual serão interpretados não somente os direitos fundamentais, mas todo o ordenamento jurídico brasileiro nas suas variadas incidências e considerações. (GARCIA, 2004, p.57).

Existem muitos desdobramentos os quais são variados desse princípio, como norma fundamental, como o dever de ser observado em tudo e também por todos, inclusive no processo legislativo, e também na condição de valor, sendo o mesmo uma fonte que anima e justifica a existência do ordenamento jurídico.

A dignidade da pessoa humana é o fundamento dos direitos fundamentais, sendo que em favor da dignidade não podem existir dúvidas, devendo ser sua realização concreta. Portanto, além dos direitos previstos expressamente no texto constitucional, entende-se que existem outros direitos fundamentais baseados na dignidade da pessoa humana da mesma maneira, mesmo que implícitos. 
Sobre o vínculo que existe entre o princípio da dignidade da pessoa humana e os direitos fundamentais, afirma Sarlet:

Verifica-se ser de tal forma indissociável a relação entre dignidade da pessoa e os direitos fundamentais que mesmo nas ordens normativas onde a dignidade ainda não mereceu referência expressa, não se poderá - apenas a partir deste dado - concluir que não se faça presente, na condição de valor informador de toda a ordem jurídica, desde que nesta estejam reconhecidos e assegurados os direitos fundamentais inerentes à pessoa humana. Com efeito, sendo correta a premissa de que os direitos fundamentais constituem - ainda que com intensidade variável, explicitações da dignidade da pessoa, por via de consequência e, ao menos em princípio (já que exceções são admissíveis, consoante já frisado), em cada direito fundamental se faz presente um conteúdo ou, pelo menos, alguma projeção da dignidade da pessoa humana (SARLET, 2011, p.55).

Entende-se, nessa perspectiva, que o Estado vincula-se aos indivíduos e à sociedade em geral por meio da dignidade da pessoa humana, já que a dignidade constitui não somente a garantia de que o indivíduo não deverá ser objeto de humilhações, mas também deve ajudar no desenvolvimento da personalidade de cada pessoa. Sobre o assunto, Doneda argumenta que:

A posição da cidadania e da dignidade da pessoa humana como fundamentos da República, juntamente com as garantias de igualdade material e formal 'condicionam o intérprete e o legislador ordinário, modelando todo o tecido normativo infraconstitucional com a tábua axiológica eleita pelo constituinte' e marcam a presença, em nosso ordenamento, de uma cláusula geral da personalidade. Tal cláusula geral representa o ponto de referência para todas as situações nas quais algum aspecto ou desdobramento da personalidade esteja em jogo, estabelecendo com decisão a prioridade a ser dada à pessoa humana, que é o valor fundamental do ordenamento, e está na base de uma série de situações existenciais, nas quais se traduz a sua incessantemente mutável a exigência de tutela (DONEDA, 2002, p.47).

O retrocesso, portanto, é proibido, devendo qualquer supressão e restrição de direito, caso fira o essencial da dignidade, ser considerada inconstitucional, uma vez que o mínimo existencial deve ser assegurado de maneira permanente.

É preciso que se imponha limites, começando antes do nascimento da pessoa até sua morte, e estes limites só poderão ser alcançados se estiverem devidamente ligados à dignidade humana. Portanto, todas as práticas bioéticas, devem levar em consideração a dignidade da pessoa humana, sendo este um valor ético que todos estão obrigados a respeitar, devendo, assim, preocupar-se com todas as técnicas de reprodução humana assistida, seleção de sexo, dentre outros. 
Sobre o assunto, diz Saldanha:

A dignidade humana compreende não somente a garantia negativa de que o ser humano não seja vítima de ofensas e humilhações, mas também a afirmação positiva do pleno desenvolvimento da personalidade de cada indivíduo. O que certamente só acontecerá se lhe for permitido desenvolvimento natural, sem manipulações externas, exceto para salvar-lhe a vida ou promover-lhe a saúde e desde que não se viole a ordem constitucional vigente (SALDANHA, 2011. p.138).

Sarlet afirma que:

Dentre as filosofias ocidentais que se ocupam com a dignidade da pessoa humana, podem ser citadas: 1) a concepção cristã (dignidade é o valor intrínseco ao ser humano, porque este foi criado à imagem e à semelhança de Deus); 2) o pensamento estoico (dignidade é a qualidade inerente ao ser humano e que o distingue dos outros seres); 3) Tomás de Aquino (autor que dá continuidade à filosofia cristã, acrescentando que também é fundamento da dignidade a autodeterminação de que o ser humano é capaz devido à sua própria natureza); 4) Giovanni Pico Della Mirandola (o ser humano é digno em razão da natureza indefinida que lhe é outorgada por Deus, significando que o homem é capaz de ser o que a sua vontade determinar, sendo assim definida a sua natureza); 5) Samuel Pufendorf (dignidade é a liberdade que o homem tem de optar conforme a sua razão); 6) Immanuel Kant (o fundamento da dignidade do ser humano é a autonomia ética deste, pois o homem é potencialmente capaz de criar suas leis, autodeterminando sua conduta; o homem é um fim em si mesmo e, por isso, jamais pode ser tratado como objeto); 7) Hegel (dignidade é a qualidade que o ser humano conquista a partir da sua cidadania e a ele é reconhecida); 8) Niklas Luhmann e Peter Hãberle (autores que destacam o aspecto histórico cultural da dignidade). A doutrina jurídica majoritária adota o pensamento kantiano no que se refere ao núcleo da noção de dignidade (SARLET, 2011, p.67).

A dignidade da pessoa humana possui como características a intangibilidade, a irrenunciabilidade e também a inalienabilidade, independendo do seu reconhecimento pelo Direito e dos comportamentos humanos, mesmo que estes não sejam considerados dignos. Assim, é dever do Estado preservar e promover a dignidade, criando condições para que a mesma seja plenamente exercida.

A força jurídica que possui os princípios constitucionais é constatada, conforme pode ser afirmado por José Afonso da Silva:

Em conclusão, a dignidade da pessoa humana constitui um valor que atrai a realização dos direitos fundamentais do homem, em todas as suas dimensões, e, como a democracia é o único regime político capaz de propiciar a efetividade desses direitos, o que significa dignificar o homem, é ela que se revela como o seu valor supremo, o valor que a dimensiona e humaniza (SILVA, 2011, p.129). 
A dignidade da pessoa humana é constituída por um valor juridico que é o mais elevado do ordenamento na Constituição, já que é um valor jurídico supremo. A sociedade que é livre, solidária e também justa, somente poderá ser oportunizada quando se elevar a dignidade da pessoa humana como um patamar de fundamento do referido Estado, sendo que este fato priorizou o aumento da personalidade das pessoas que são compostas a sociedade, como podem ser vistos durante o texto constitucional em vários artigos em que consta a dignidade da pessoa humana.

\section{Conforme afirma Bonavides:}

Uma Constituição que parte da dignidade humana e de sua proteção deve preocupar-se com que essa dignidade (incluindo suas vinculações) seja vista com um objetivo pedagógico - desde as escolas até a regulamentação da atividade de radiodifusão -, mesmo onde a dignidade não esteja textualmente como constituindo objetivo pedagógico. Da previsão textual da dignidade deriva sua condição do objetivo pedagógico e educativo. A Constituição assume este compromisso perante si própria. Toda a problemática do poder, toda a porfia de legitimação da autoridade e do Estado no caminho da redenção social há de passar, de necessidade, pelo exame do papel normativo do princípio da dignidade da pessoa humana. Sua densidade jurídica no sistema constitucional há de ser, portanto, máxima e se houve reconhecidamente um princípio supremo no trono da hierarquia de normas, esse princípio não deve ser outro senão aquele em que todos os ângulos éticos da personalidade se acham consubstanciados (BONAVIDES, 2014, p. 87).

Conforme versa a Constituição Federal de 1988 em seu artigo $1^{\circ}$, inciso III, o Estado Democrático de Direito possui como fundamentação a dignidade da pessoa humana, em que se trata do que é denominado de princípio máximo, ou superprincípio, ou macroprincípio. Portanto, o Direito de Família é o que possui a maior ingerência com a Dignidade da Pessoa Humana (TARTUCE, 2017).

Sobre a interação família e dignidade, afirma Gustavo Tepedino:

A família, embora tenha o seu prestígio ampliado pela Constituição da República, deixa de ter valor intrínseco, como uma instituição meramente capaz de merecer tutela jurídica pelo simples fato de existir. A família passa a ser valorizada de maneira instrumental, tutelada como um núcleo intermediário de desenvolvimento da personalidade dos filhos e de promoção da dignidade de seus integrantes. (TEPEDINO, 2011, p.399). 


\section{DA EDUCAÇÃO INCLUSIVA}

Conforme já salientado, a dignidade da pessoa humana é um dos fundamentos da República brasileira, previsto no artigo $1^{\circ}$ da Constituição federal, e constitui um princípio de incomensurável valor jurídico para todo o ordenamento político-normativo brasileiro, dado o foco que oferece às pessoas naturais e seu bem-estar na vida em sociedade.

$\mathrm{Na}$ esfera jurídica, o ordenamento internacional, bem como diversas constituições nacionais, instituiu a dignidade da pessoa humana como princípio basilar: começou com a Declaração Universal dos Direitos do Homem e do Cidadão, cujo artigo $1^{\circ}$ expõe que "todos os seres humanos nascem livres e iguais em dignidade e direitos. São dotados de razão e consciência e devem agir em relação uns aos outros com espírito de fraternidade".

Anos mais tarde, as Constituições Contemporâneas, escritas no período do Segundo Pós-Guerra sob a luz do neoconstitucionalismo, mostraram demasiada preocupação no que diz respeito aos direitos individuais e à democracia. Em 1988, a Constituição Cidadã restaurou a preeminência do respeito aos direitos fundamentais, proclamados juntamente com significativa série de direitos sociais. Nesse sentido, cabe dizer que hoje a dignidade da pessoa humana é um dos fundamentos principais, senão o fundamento do Estado Democrático de Direito.

Nesse jaez, compreende-se que os objetivos fundamentais elencados pelo texto constitucional em seu artigo $3^{\circ}$, quais sejam: a construção de uma sociedade livre, justa e solidária; a garantia do desenvolvimento nacional; a erradicação da pobreza e da marginalização, além da redução das desigualdades sociais e regionais; e, ainda, a promoção do bem de todos, sem preconceitos de origem, raça, sexo, cor, idade e quaisquer formas de discriminação, têm como pressuposto a atividade estatal direcionada à promoção da dignidade da pessoa humana. Isto é, a partir do devido cumprimento e respeito da dignidade humana, consequentemente as pessoas tornam-se aptas ao bemestar e, assim, os objetivos que se relacionam à vida em sociedade passam a ser realizáveis de maneira concreta.

A dignidade é uma forma de valorização do ser humano. Destina-se a proteger o indivíduo de qualquer humilhação ou situação vexatória, proporcionar a possibilidade de desenvolvimento e crescimento pessoal. É valor supremo da existência humana. A partir 
dela, projetam-se direitos invioláveis, chamados direitos fundamentais, e dessas circunstâncias é possível depreender que a vida digna é aquela em que se encontram efetivadas as prerrogativas e assegurados os direitos sociais, relacionando-se, em geral, a saúde, alimentação, segurança, previdência social, moradia, trabalho, lazer e educação, por exemplo.

Art. $6^{\circ}$ São direitos sociais a educação, a saúde, a alimentação, o trabalho, a moradia, o transporte, o lazer, a segurança, a previdência social, a proteção à maternidade e à infância, a assistência aos desamparados, na forma desta Constituição. [...]

Art. 205. A educação, direito de todos e dever do Estado e da família, será promovida e incentivada com a colaboração da sociedade, visando ao pleno desenvolvimento da pessoa, seu preparo para o exercício da cidadania e sua qualificação para o trabalho. (BRASIL, 1988).

Todo cidadão, com base no princípio da igualdade, tem direito a uma vida digna, sendo-lhe assegurado o devido respeito, resguardados os seus direitos e reconhecidos os seus deveres como cidadão. Ademais, o princípio da dignidade humana garante também a liberdade de as pessoas determinarem os rumos de sua própria vida, sem a interferência de qualquer pessoa, agindo, assim, com total autonomia ao fazer suas escolhas.

Nenhum país alcança pleno desenvolvimento, se não garantir, a todos os cidadãos, em todas as etapas de sua existência, as condições para uma vida digna, de qualidade física, psicológica, social e econômica. A educação tem, nesse cenário, papel fundamental, sendo a escola o espaço no qual se deve favorecer, a todos os cidadãos, o acesso ao conhecimento e o desenvolvimento de competências, ou seja, a possibilidade de apreensão do conhecimento historicamente produzido pela humanidade e de sua utilização no exercício efetivo da cidadania.(BRASIL, 2004. p.8)

Diante desse contexto, entendendo-se que todos os seres humanos têm direito à dignidade e à promoção do bem-estar, que representa, ainda, um dos objetivos da república brasileira, argumenta-se que o Estado deve se responsabilizar pela promoção do bem-estar social, de modo que as pessoas possam se desenvolver e fazer suas escolhas num ambiente em que as diversidades sejam igualmente respeitadas, sem patrocínio de qualquer discriminação no tocante a gênero, origem, raça, sexo, cor, idade, dentre outras condições.

Sabe-se que o Estado Democrático de Direito é multifacetado, composto por características plurais e pessoas as mais diversas possíveis. Isto posto, e entendendo-se a dignidade interseccional, é necessário que a educação promovida no país seja, acima de 
tudo, inclusiva, democraticamente construída, educação esta prevista na Constituição federal como direito social e como pressuposto "para o exercício da cidadania e sua qualificação" (BRASIL, 1996), segundo a Lei de bases e diretrizes para a educação nacional.

A educação inclusiva, assim, faz alusão a um modo de ensino e aprendizagem em que as diferenças são admitidas como diversidades. Desenvolvida com base numa dinâmica de redes de apoio, a educação inclusiva é uma modalidade cujo processo educativo é basicamente um "processo social em que todas as pessoas, com deficiência ou não, têm o direito à escolarização. É uma educação voltada para a formação completa e livre de preconceitos que reconhece as diferenças e dá a elas seu devido valor". (PROESC).

Isso significa que a educação inclusiva, ao reconhecer e respeitar as diversidades existentes entre as pessoas, até mesmo pelo fato de entender que qualquer pessoa pode apresentar necessidades especiais em algum momento da vida escolar, organiza-se para que, independentemente de etnia, gênero, cor, raça, religião, deficiência, todas tenham suas necessidades atendidas e potencialidades desenvolvidas. Nas instituições que adotam a educação inclusiva, os alunos são sujeitos de direito e foco da ação educacional, sendo prioridade dessa ação "garantir a sua caminhada no processo de aprendizagem e de construção das competências necessárias para o exercício pleno da cidadania”. (BRASIL, 2004. p.9).

Tendo em vista esse cenário, compreende-se que a educação inclusiva é um instrumento do qual o Estado brasileiro deve lançar mão para que as diversas situações encontradas no tecido social sejam, de fato, respeitadas. Assim, a partir de tal respeito, os princípios e demais direitos constitucionalmente previsto tornam-se concretos, de modo que a dignidade da pessoa humana seja uma realidade capaz de promover o bem-estar geral.

\section{CONSIDERAÇÕES FINAIS}

O presente artigo analisou, de forma ampla, os princípios constitucionais da dignidade humana e do bem-estar social, que constitui, també, objetivo fundamental da 
república brasileira de acordo com as normas programáticas regidas na Constituição de 1988.

Diante da perspectiva constitucional traçada para a observação da dignidade, princípio basilar para a gestão do Estado Democrático de Direito, uma vez que focaliza a pessoa humana como sujeito de sireitos e obrigações perante o ente estatal, o artigo introduz a questão da inclusão a partir da educação, direito social indispensável para a promoção do bem-estar.

Assim, considerando a composição heterogênea do Estado Democrático de Direito, cuja fundamentação é a dignidade da pessoa humana, e entendendo-se ser necessário o respeito a todas as diferenças para a harmônica vida em sociedade, de modo que todas as pessoas tenham acesso a seus direitos e possam exercer as suas prerrogativas, a educação inclusiva aparece como um instrumento a ser lançado mão pelo Estado para que a dignidade humana e o bem-estar sejam realidades cada vez mais próximas do povo brasileiro.

A educação inclusiva transforma a escola em um espaço de todos, uma vez que compreende a educação especial no interior da escola regular. Assim, pode ser encarada como uma modalidade de ensino e aprendizagem que, diferente do modo tradicional ou padrão, entende as diversidades das pessoas e valoriza-as, de maneira que tais diversidades tornam-se fomento para a defesa da pluralidade e consequente promoção de qualidade de vida às pessoas.

Visto que a educação inclusiva funciona com base numa rede de apoio, é essencial que instituições, como as próprias escolas e as famílias, além dos educadores trabalhem juntos, de maneira a propiciarem uma ampla participação, oportunidades e experiências para todas as pessoas envolvidas no processo educativo. Entende-se que a partir de tal dinâmica, as pessoas têm acesso a uma formação completa e livre de preconceitos, o que é essencial para o bom funcionamento da democracia.

Nesse sentido, o artigo defende a promoção de uma educação inclusiva como questão de ordem constitucional, sob os prismas da dignidade da pessoa humana e do bem-estar social, isto é, tal educação como meio de se promover mais respeito na sociedade e de se alcançar a dignidade das pessoas com o desenvolvimento de seu bemestar atrelado à pluralidade do Estado Democrático de Direito brasileiro, o qual foi 
instituido em 1988 com a promulgação do texto constitcuional então vigente. Contudo, alerta-se que para se assegurar a participação de todas as pessoas, seja quais forem as interseccionalidades que as toquem, é fundamental a compreensão das especificidades e da pluralidade como condição da democracia.

\section{REFERÊNCIAS}

ALARCÓN, Pietro de Jesús Lora. Patrimonio Genético Humano e sua proteção na Constituição Federal de 1988. São Paulo: Editora Método, 2014.

BARROSO, Luis Roberto. Curso de direito constitucional contemporâneo: os conceitos fundamentais e a construção do novo modelo. São Paulo: Saraiva, 2009.

BONAVIDES, Paulo. Curso de Direito Constitucional. 4.ed. São Paulo: Malheiros, 2014.

BRASIL. Constituição da República Federativa do Brasil de 1988. Disponível em:

http://www.planalto.gov.br/ccivil 03/constituicao/constituicao.htm Acesso em 08 nov. 2021.

BRASIL. Lei no 9.394, de 20 de dezembro de 1996. Estabelece as diretrizes e bases da educação nacional. Disponível em: http://www.planalto.gov.br/ccivil_03/leis/19394.htm Acesso em 08 nov. 2021.

BRASIL. Ministério da Educação. Educação inclusiva: a escola. Organização de Maria Salete Fábio Aranha. - Brasília: Ministério da Educação, Secretaria de Educação Especial, 2004.

DONEDA, Daniel. Os direitos da personalidade no novo Código Civil. In TEPEDINO, Gistavo (coord.). A parte geral do Novo Código Civil: Estudos na perspectiva civilconstitucional. Rio de Janeiro: Renovar, 2002.

GARCIA, Maria. Limites da ciência: A dignidade da pessoa humana: A ética da responsabilidade. São Paulo: Editora Revista dos Tribunais, 2004.

MENDES, Gilmar Ferreira et. al. Curso de direito constitucional. $4^{a}$ ed. São Paulo: Saraiva, 2010.

MORAES, Alexandre de. Direito Constitucional. 29a ed. São Paulo: Atlas, 2013.

NERY Júnior, Nelson; NERY, Rosa Maria de Andrade. Constituição Federal comentada e legislação constitucional. 2 ed. São Paulo: Revista dos Tribunais. 2006.

PROESC. Educação inclusiva: quais os pilares e o que a escola precisa fazer? Disponível em: http://www.proesc.com/blog/educacao-inclusiva-o-que-a-escola-precisa-fazer/ Acesso em 08 nov. 2021.

SALDANHA, Nelson. Pela preservação do humano: antropologia filosófica e teoria política. 2ed. São Paulo: A Girafa, 2011.

SARLET, Ingo Wolfgang. A eficácia dos direitos fundamentais. Porto Alegre: Livraria do Advogado, $10^{\mathrm{a}}$ ed.,2011.

SILVA, José Afonso da. Curso de Direito Constitucional Positivo. 27 ed. São Paulo: Malheiros, 2011. 
SILVA, José Afonso da. Direito Constitucional Positivo. 31 ed. Malheiros: São Paulo, 2008.

TEPEDINO, Gustavo. Temas de Direito Civil. Rio de Janeiro: Renovar, 2011.

USP - Universidade de São Paulo. Biblioteca virtual de Direitos Humanos. Declaração de Direitos do Homem e do Cidadão - 1789. Disponível em:

http://www.direitoshumanos.usp.br/index.php/Documentos-anteriores-\%C3\%A0cria\%C3\%A7\%C3\%A3o-da-Sociedade-das-Na\%C3\%A7\%C3\%B5es-at\%C3\%A9-

1919/declaracao-de-direitos-do-homem-e-do-cidadao-1789.html Acesso em 08 nov. 2021.

Recebido em: 10/12/2021

Aprovado em: 10/01/2022

Publicado em: 14/01/2022 